\title{
APROXIMACIÓN A LA ESTRUCTURA DE LAS SECUENCIAS DE APERTURA Y CIERRE EN LAS CONVERSACIONES TELEFÓNICAS EN ESPAÑOL
}

\author{
ANTONIO MANUEL ÁviLA MUÑOZ \\ (Universidad de Málaga)
}

\begin{abstract}
RESUMEN
With this work we intend to contribute to a better understanding of the mechanisms that rule conversation. These mechanisms have generally proved not to be either simple or even easy to approach. The presence of conversation in our daily life makes it a basic way of communication, despite its intricate structure, often conditioned by the close social interaction among the participants. The understanding of such a structure requires the study of the patterns that the speaker is able to produce and the listener to understand. This study proposes a sociolinguistic revision as far as oral speech is concerned by means of the study of a specific type of oral interaction: telephone conversations.
\end{abstract}

\section{Principios básicos de la conversación}

La conversación es el modelo elemental más válido que existe del uso de la lengua y quizás por ello ha sido objeto de investigación en distintos campos del saber, la mayor parte de las veces encaminados a profundizar en el estudio de la interacción verbal'. El Análisis de la Conversación ${ }^{2}$ como disciplina independiente pretende descubrir las organizaciones sistemáticas del habla a través de la citada interacción. Las manifestaciones de estas organizaciones

1 La interacción que ocurre de manera natural en el proceso conversacional ha marcado la perspectiva de los estudios sobre esta materia desde el principio. Así, H. SACKS y sus seguidores ya centraron en los orígenes del Análisis de la Conversación su objetivo en la organización de la interacción conversacional misma.

A. M. CESTERO (1994), expone ampliamente el marco teórico en que se sitúan la mayoría de los trabajos más relevantes sobre el estudio de la conversación desde los orígenes de esta disciplina hasta nuestros días. 
constituyen un conjunto de soluciones metódicas a los problemas que los hablantes deben resolver en cada acto conversacional. Por tanto, la conversación tendrá tantas formas como pretensiones y objetivos se propongan los participantes en cada ocasión particular de habla ${ }^{3}$. No obstante, en todas las conversaciones existen una serie de patrones que han llevado a considerarla de modo general, como intercambios de habla con orden, duración y contenido variable de turnos ${ }^{4}$. Por tanto, el fin que guía a los investigadores de la conversación es llegar a conocer los mecanismos de producción que los hablantes-oyentes empleamos para tratar algunos aspectos conductuales, tales como la entrada coordinada en conversación, las tomas de turno, los cierres conversacionales, la presentación de problemas durante el proceso y las soluciones adoptadas en cada caso.

Uno de los fenómenos conversacionales que antes despertó el interés de los analistas fue el de la alternancia de turnos y las cuestiones conexas a dicha alternancia (asignaciones conscientes de turnos, mantenimientos, suspensiones voluntarias, interrupciones, silencios, imbricación conversacional, etcétera). Pronto se descubrió que determinados turnos demandaban la aparición de otros posteriores con unas características específicas. Surgía así el concepto de pares de adyacencia para explicar la existencia de turnos pareados en el discurso ${ }^{5}$ producidos por hablantes diferentes y ordenados de manera que una primera parte requiere necesariamente la aparición de otra segunda parte para cerrar el proces $0^{6}$. Por ejemplo a un saludo corresponde otro saludo o a una pregunta una respuesta, etcétera.

El concepto de par de adyacencia fue retomado por los investigadores y se le dio un papel fundamental en la organización secuencial de la conversación. Los analistas pronto extendieron la secuencia simple de dos turnos de palabra a otros posteriores, considerándose entonces no tanto los pares simples, sino secuencias más extensas y complejas unidas por una coherencia temática y/o funcional que motivaron un especial interés por la organización general de la conversación. Sin embargo, el sistema temático suele ser de tal envergadura que no existen todavía principios generales que expliquen su organización. Sabemos, eso sí, que la estructura temática necesita de unos procedimientos específicos que aseguren la aparición de determinados temas y la relación natural de unos con otros. La sucesión semántica necesita de unos procedimientos que hagan coherente el paso de unos temas a otros. Estos procedimientos son tanto verbales como no verbales y ni unos ni otros han sido tratados hasta el momento con el debido rigor, a pesar

C. WEST y D. H. ZIMMERMAM (1982), págs. 506-541, esp. págs. 506-510.

H. SACKS, E. SCHEGLOFF y G. JEFFERSON (1974), págs. 696-731.

E. A. SCHEGLOFF y H. SACKS (1973).

S. C. LEVINSON (1983), modifica sustancialmente el concepto basándose en que la cualidad de adyacencia no siempre queda de manifiesto, pues no todas las segundas partes son adyacentes a las primeras. Él prefiere hablar de pares pertinentes o esperables, aunque no se den de manera inmediata. 
de su frecuencia elevada de aparición y de su función, que es la de mantener el desarrollo de la interacción en forma secuencial.

No obstante, debemos a los últimos avances en el Análisis de la Conversación la comprobación de la existencia de reglas en el habla casual a través de estudios empíricos que permiten el examen del uso de estrategias recurrentes. Sin embargo, tales reglas no son de obligatorio seguimiento, sino que, más bien, podríamos definirlas como reglas preferenciales. Al hablante se le presentan siempre varias formas alternativas de actuar y de interpretar.

\section{Características generales de las conversaciones telefónicas ${ }^{7}$}

La organización de las conversaciones telefónicas está orientada por los participantes $y$, por tanto, estos reconocen de alguna manera su organización estructural ${ }^{8}$.

Las conversaciones telefónicas son de especial utilidad para realizar análisis generales de la conversación debido a las ventajas metodológicas que conllevan, pues pueden ser obtenidas de manera rápida, limpia y fiable. Además, la variedad que se puede conseguir con este tipo de conversaciones nos asegura una tipología conversacional heterogénea, con elementos espontáneos y naturales. Además, en ellas sólo se produce comunicación verbal, es decir, alejan las complicaciones que supone el análisis de la comunicación no verbal producidas en la conversación cara a cara?.

Como ya puso de manifiesto D. Godard ${ }^{1()}$, las llamadas telefónicas, consideradas como actos de habla, están abiertas a distintas interpretaciones socioculturales y su estructura básica puede simplemente ser el resultado de ciertas asunciones culturales y sociales puestas de manifiesto en la interacción que se establece entre los hablantes. El desconocimiento de las normas de interacción existentes en la comunidad de habla norteamericana provocó en Godard una seric de situaciones anómalas al teléfono, pues no coincidían los esquemas de interacción básicos que traía de Francia con los existentes en los Estados Unidos de América.

S. C. LEVINSON (1983) lleva a cabo un detallado estudio sobre las peculiaridades de las conversaciones telefónicas donde podemos encontrar una interesante caracterización de las mismas.

Está por demostrar que este reconocimiento se lleve a cabo de manera implícita o explícita. Levinson (1983) asegura el reconocimiento implícito por parte de los hablantes de la organización conversacional general, basándose en el hecho de que estos son capaces de resolver las dificultades que puedan presentarse a lo largo del proceso conversacional recurriendo a procedimientos de enmienda regularizados (pág. 307).

No dudamos de la importancia de la comunicación no verbal, pero también sabemos que la dificultad obvia que entraña el estudio de los factores no verbales ha sido la causa de que apenas haya tenido sitio en el Análisis de la Conversación. Sólo en época reciente algunos investigadores han antepuesto a esta dificultad la importancia de su análisis y se han especializado en el estudio de la interacción existente entre el hecho lingüístico y el comportamiento no verbal. Cf. C. GOODWIN (1979), A. KENDON (1982).

(1) D. GODARD (1977), págs. 209-219. 
Las conversaciones telefónicas poseen por lo general comienzos claros y conclusiones cuidadosamente organizadas, lo que podríamos denominar turnos de apertura y cierre conversacional, que pertenecen a las secuencias marco que señalábamos arriba. Se trata de los grupos de turnos que son emitidos a modo de apertura o cierre de una conversación. Lógicamente, la secuencia de apertura inicia la conversación y la secuencia de cierre marca su final. Las secuencias marco han sido desde siempre estudiadas en el contexto de las conversaciones telefónicas pues es en este tipo de conversaciones donde se aprecia su estructura de manera más clara e inmediata.

\section{Estudios del discurso en comunidades de habla hispana}

Aunque el Análisis de la Conversación se ha desarrollado en los últimos veinticinco años a partir del enfoque empírico que la tradición etnometodológica estadounidense fue capaz de introducir en este campo de investigación, parece que el interés por el análisis del discurso del español hablado no se ha despertado hasta fecha relativamente reciente.

Uno de los primeros en mostrar interés en este sentido fue Moreno Fernández. En 1988 realizó una revisión bibliográfica crítica sobre la cuestión ${ }^{11}$, donde considera al Análisis de la Conversación como deudor en parte del desarrollo de la Etnografía de la Comunicación. Ha contribuido asimismo al estudio del habla coloquial en comunidades de habla hispana en lo que podríamos considerar trabajos lingüísticos centrados en las repercusiones que los hechos sociales de diversa naturaleza pueden llegar a tener sobre el desarrollo de las lenguas naturales en el seno de las comunidades que las utilizan ${ }^{12}$.

El grupo de investigación Valencia Español Coloquial, que dirige Antonio Briz, ha impulsado con fuerza las investigaciones generales sobre el discurso. Ya nos han ofiecido una serie de estudios sobre el análisis del discurso a partir de un corpus básicamente oral, extraído directamente de la conversación espontánea y de otro lipo de discursos ${ }^{13}$. Una de las aplicaciones más interesantes de este corpus hasta el momento ha sido la llevada a cabo por Beatriz Gallardo Paúls, quien se ha interesado, entre otros asuntos, por las relaciones que unen a los participantes en un encuentro verbal ${ }^{14}$.

\footnotetext{
F. MORENO (1988), págs. 37-59.

F. MORENO (1986) (1989a, b, c).

A. BRIZ(1995).
}

B. GALLARDO PAÚLS (1990, 1991a, 1991b, 1992, 1993a, 1993b) ha estudiado al detalle algunos de los rasgos fundamentales a los que se subordinan las tomas de turno conversacional, como los vínculos que relacionan a los hablantes, la retroalimentación, la elaboración colaborativa de los enunciados o la progresión acumulativa que caracteriza la información bajo la denominación general do dimamismo conversacional. Además, debemos a esta autora el estudio de conjunto que recoge y cjemplifica todas las secuencias conversacionales posibles en español (1993). 
Ana María Cestero', por su parte, ha profundizado también en el conocimiento sobre el intercambio del habla, preocupándose especialmente por conocer cómo se produce y cómo funciona el intercambio de turnos de palabra en la conversación en lengua española. Decidida a descubrir el mecanismo de intercambio de turnos de habla que opera en la conversación, constata que tales mecanismos y los elementos y fenómenos relacionados con él pueden ser modificados, pues están determinados por factores sociales y contextuales ${ }^{16}$.

\section{El proceso empírico}

\subsection{Metodología empleada}

Partiendo de la base de que el estudio de la interacción social ha de realizarse mediante el análisis de datos captados de la realidad y ocurridos de manera natural, poseemos un corpus de datos extenso capaz no sólo de ser analizado, sino reanalizado tantas veces como fines persigamos ${ }^{17}$. Además, el corpus nos permite la comparación periódica de los datos a través del tiempo, ya que se trata de una base textual ampliable y revisable. Para la elaboración del corpus general se siguió una metodología básicamente apoyada en dos fases:

- Recogida de materiales mediante la grabación de discursos naturales obtenidos en determinadas situaciones.

- Transcripción detallada de los materiales grabados según las Normas de Codificación TEI ${ }^{18}$.

Para el estudio que presentamos procedimos a realizar veinte grabaciones telefónicas efectuadas en el mes de noviembre de 1995 en la ciudad de Málaga. Cabe destacar que en la mayoría de los casos ninguno de los interlocutores conocía la existencia de la grabadora y, en el peor de los casos, sólo uno de ellos cra consciente de estar siendo objeto de estudio ${ }^{19}$. Posteriormente, y previo consentimiento de los sujetos implicados, se procedió, como con el resto del corpus, a realizar una minuciosa transliteración de la conversación ${ }^{20}$.

15 A. M. CESTERO (1994), opus cit.

16 La bibliogralía sobre estudios de este tipo en español es evidentemente más extensa y en los últimos años, por fortuna, se está produciendo una eclosión en este sentido. Aquí, debido a razones obvias, solo citamos los anteriores para dar una idea de conjunto de la situación de la cuestión en trabajos que toman como partida la conversación en comunidades de habla hispana. De cualquier manera, el lector interesado puede encontrar referencias en L. CORTÉS (1996), págs. 35-55.

17 El corpus al que hacemos referencia es producto y base del corpus oral de la Universidad de Málagil (Proyecto de Investigación de las Variedades Vernáculas Andaluzas Proyecto V.U.A. PB941467.CO2 de la DGYCIT).

is C. M. SPERBERG-McQUEEN y L. BURNARD (1990), edición española de F. MARCOS MARÍN (1992).

1.) Para lograr la máxima nitidez en el sonido se acopló un aparato grabador (STEED TT-O2M) a la cajja de entrada de la línea de teléfono capaz de conectar directamente el mismo al MINI DISC digital.

211 Para un acercamiento al sistema de etiquetado utilizado y los problemas gencrales derivados de las características de nuestro corpus, J. A. VILLENA (1994). 


\subsection{Análisis}

Como ha quedado expuesto más arriba, las conversaciones telefónicas son el exponente más claro de las llamadas secuencias marco donde se da una serie de grupos de turnos que son emitidos a modo de apertura o cierre. En la apertura, existe un esquema básico que raramente sufre modificaciones: el teléfono suena, el receptor hace notar su participación (normalmente con un sencillo diga, ¿sí? o similar, después de lo cual la persona que provocó la llamada tiende a saludar e identificarse. El hecho de que el que descuelga el teléfono sea el primero en hablar constituye el pistoletazo de salida para el inicio de un esquema del tipo $a b a b a b$ donde $a$ y $b$ son las partes de la conversación ${ }^{21}$. En condiciones normales, podemos considerar el timbre del teléfono y la respuesta por parte del que contesta como un todo unitario, pues sin esta respuesta no existiría conversación (simplemente pensaríamos que en ese momento no se encuentra nadie en casa). Esa unidad primera es lo que confiere a la apertura conversacional el rango de actividad coordinada en la que se requieren dos partes. Con la puesta en funcionamiento de este elemento unitario damos a entender que existe alguien que marca los números del dial y hace sonar el aparato telefónico, interesado en iniciar una conversación, y alguien que descuelga y responde, dando a entender su disponibilidad para entablar la conversación, para lo cual bastará con una de las fórmulas apuntadas arriba: ¿sí? ¿digame?22. A partir de este momento está dado el primer paso y la conversación se entenderá abierta ${ }^{23}$. A continuación, la persona que llama da la razón de la llamada, con lo cual entramos de lleno en lo esencial del mensaje. Se suele considerar que en este esquema básico de apertura la persona que realiza la llamada parte con la ventaja de conocer la identidad del interlocutor con el que desea hablar, mientras que el que responde al teléfono no sabe en un primer momento a quién habla. Los ejemplos de este tipo de esquema básico son numerosos y se dan tanto entre hablantes entre los que existe cierta intimidad como entre los que no la hay ${ }^{24}$. Los esquemas estructurales ofrecen alternativas atendiendo a las elecciones y preferencias en un marco de actuación aceptado por los hablantes y coherente, a la vez que «negociable».

21 Sobre esquemas rituales en la conversación existe una amplia bibliografía que puede consultarse en F. MORENO (1988), opus cit.

22 No ocurre lo mismo en países como Francia donde, según Godard, el hecho de descolgar el aparato y pronunciar un Allo? no parece indicar siempre una disponibilidad para comenzar una conversación telefónica, ya que el esquema básico de apertura es, en este país, más complejo, y consta, además de los pasos señalados de a) timbre y b) respuesta, de c) comprobación del número al que se llama, d) excusas por la llamada, e) identificación personal del que llama y f) inicio de la conversación propiamente dicha.

23. Esto será así siempre que los interlocutores se reconozcan, pues en caso contrario la apertura puede desembocar en una situación similar a la descrita por Godard.

24 Nótese cómo en el primer ejemplo, referido a hablantes con una relación bastante íntima, el simple timbre o tono de voz de la persona que efectúa la llamada es suficiente para que el receptor lo reconozca, con lo cual la identificación, en este caso, se realiza a través de los citados parámetros. 


\section{Representación gráfica de las organizaciones estructurales básicas:}

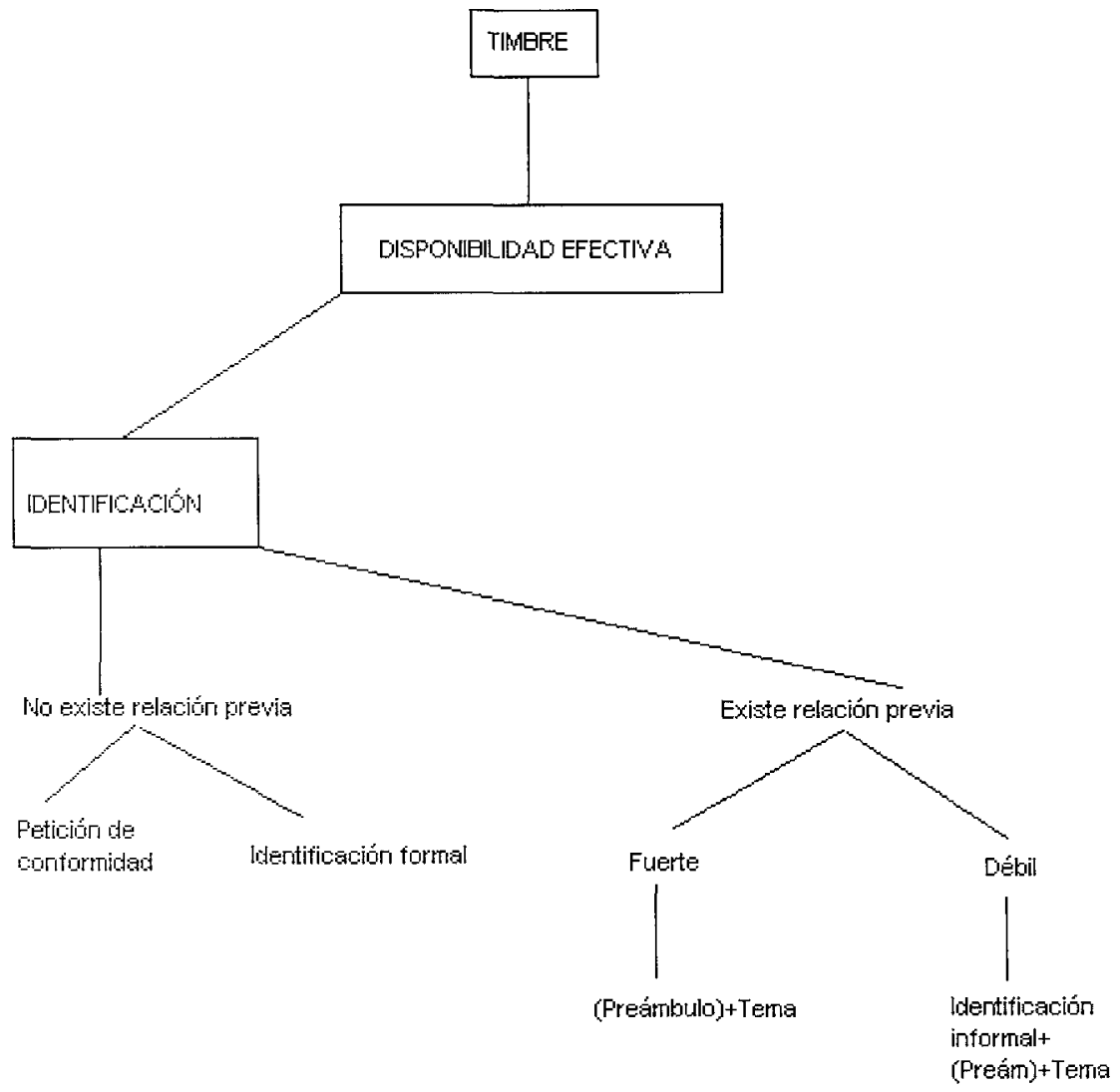

Ejemplo $1^{25}$. Esquema básico de apertura telefónica entre interlocutores muy conocidos

$<$ Mc=mujer, 25 años, estudios medios, administrativo $>$

$<\mathrm{G}=$ hombre, 26 años, estudios superiores, investigador $>$

$<$ origen $=\mathrm{Mc}=\mathrm{G}=$ Málaga $>$

$<$ roles $=\mathrm{Mc}=\mathrm{G}=$ amigos $>$

$<$ limbre>

Mc.- ¿sí? (Disponibilidad. Conversación abierta)

G.- jhola <nombre propio $>$ Mercedes ${ }^{26}$ </nombre propio $>$ ! (Identificación+muestra de voz)

25. Antes de los ejemplos propiamente dichos se ofrecen los datos mínimos de los participantes en los mismos a modo de documentación sociobiográfica y de relaciones interpersonales entre los sujetos. 
Mc.- ¡buenas noches <nombre propio $>$ Gonzalo </nombre propio $>$ ! $<$ apelativa $>$ dime $<$ /apelativa $>$. (Aceptación, existe relación previa)

G.- ¿estabas dormi $<(d)>a$ ? (Preámbulo)

Mc.- no $\langle$ risas $=M c\rangle$. (/Preámbulo)

G.- mira "¿por qué no le dices a tu prima <cláusula no completa> (Tema)

Mc.- sí.

G.- que $(\rightarrow)$ ' <estilo indirecto> a ver dónde están las llaves que yo no las encuentro </estilo indirecto $>$.

Ejemplo 2. Esquema básico de apertura telefónica entre conocidos

$<\mathrm{J}=$ hombre, 42 años, estudios superiores, profesor $>$

$<\mathrm{L}=$ hombre, 26 años, estudios superiores, investigador $>$

$<$ origen $=\mathrm{J}=$ Granada $>$

$<$ origen $=\mathrm{L}=$ Málaga $>$

$<$ roles $=\mathrm{J}=\mathrm{L}=$ compañeros de trabajo $>$

$<$ timbre>

J.- ¿dígame? (Disponibilidad. Conversación abierta)

L.- $i<$ nombre propio $>$ Juan < $<$ nombre propio $>$ ? (Identificación+Muestra de voz)

J.- sí. (Existe relación previa. Débil)

L.- hola' soy <nombre propio > Lucas </nombre propio $>$. (Identificación informal)

J.- hola ${ }^{\neg}<$ nombre propio $>$ Lucas </nombre propio $>$. (Aceptación)

L.- ¿qué pasa? $\urcorner$ hombre $\urcorner$ buenos días. (Preámbulo)

J.- ¿qué hay? (Preámbulo)

L.- mira <suspensión voluntaria $>\ldots$ '<vacilación $>$... ¿tú vas a ir mañana a la olicina? (Tema)

Otras veces, sin embargo, los pares de adyacencia se rompen debido a que la primera parte del par no tiene correspondencia en la segunda. El debate de la coherencia y cohesión del discurso ha provocado cierta polémica entre los estudiosos $^{27}$. El caso de la presumible falta de coherencia en los pares de adyacencia lógicos en las aperturas de las llamadas telefónicas es un caso más que vicne a demostrar que no siempre las conexiones lógicas entre las unidades lingüísticas se hacen explícitas en las conversaciones. Sin embargo, es evidente que no estamos ante una secuencia arbitraria de enunciados, más bien al contrario, los hablantes son capaces de identificar las conexiones específicas que se establecen entre los enunciados y que no siempre corresponden a lo que dicta la lógica ni las leyes gramaticales. Incluso, existen autores que partiendo de este hecho proponen una ampliación de la noción de gramática, de manera que no sólo abarque la buena formación de las oraciones, sino también del discurso

36 En todos los casos en que aparecen datos personales de los informantes, estos han sido nodilicados para preservar la identidad de los sujetos, pero en ningún caso afecta esta modificación a la sustancia de la información que transmiten.

27 T. van DIJK (1984); M. A. K. HALLIDAY y R. HASAN (1977); J. R. SEARLE (1971); D. BLAKEMORE (1992), págs. 275-300, especialmente 277 en adelante. 
atendiendo a la pragmática ${ }^{28}$. Lógicamente, el saludo requiere saludo, las preguntas requicren contestación, etc. No siempre es así, aunque como demostraremos en los siguientes ejemplos, la pertinencia en esta ruptura de pares sc hace patente, toda vez que la comunicación se hace fluida y en ningún momento se pone en peligro su buen funcionamiento. Es más, cuando los hablantes rompen estos pares lógicos nunca se corre el riesgo del más mínimo coste adicional de procesamiento por parte del oyente, ya que siempre se incorporan elementos nuevos que hacen avanzar el proceso comunicativo ${ }^{29}$. En los siguientes ejemplos demostraremos cómo se cumple el principio de pertinencia, ya que los enunciados son pertinentes siempre que transmitan información pertinente y aquí esta premisa se lleva a cabo.

Ejemplo 3. Ruptura de pares de adyacencia

a)

$$
\begin{aligned}
& <B=\text { mujer, } 59 \text { años, estudios básicos, ama de casa }> \\
& <\mathrm{A}=\text { hombre, } 26 \text { años, estudios superiores, investigador } \\
& <\text { rigen }=\mathrm{B}=\mathrm{A}=\mathrm{Mál} \text { laga }> \\
& <\text { roles }=\mathrm{B}=\mathrm{A}=\text { familia } \\
& <\text { timbre> } \\
& \text { B.- } \text { ¿diga? (Disponibilidad. Conversación abierta) } \\
& \text { A.- ¿se viene papá? (Muestra de voz. Relación muy fuerte. Tema) } \\
& \text { B.- sí ' ha salido hace cinco minutos. (Reconocimiento. Aceptación) }
\end{aligned}
$$

Observamos aquí como el par de adyacencia se ha roto, pues a una primera parte del par interrogación ¿diga?, debería corresponderle o una respuesta o una identificación por parte de la persona que llama, pero en ningún caso otra pregunta ¿se viene papá?. En cualquier caso, los interlocutores son lo suficientemente conocidos como para permitirse la licencia de romper la lógica de adyacencia e identilicarse primero sin ningún tipo de ritual específico para transmitir información después, haciendo cumplir el principio de pertinencia.

b)

$$
\begin{aligned}
& <\mathrm{l}=\text { hombre }> \\
& <\mathrm{Mc}=\text { mujer, } 26 \text { años, estudios superiores, maestra }> \\
& <\text { origen=Mc=Málaga }> \\
& <\text { roles }=\mathrm{I}=\mathrm{Mc}=\text { no existe relación previa }> \\
& <\text { timbre }> \\
& \text { l.- }<\text { ruido=música }>\text { ¿sí? (Disponibilidad. Conversación abierta) }
\end{aligned}
$$

28 G. GAZDAR (1979); T. van DIJK, opus cit., págs. 6-7.

29 El principio de pertinencia comunicativa fue expresado por B. SPERBER y D. WILSON (1986), donde hacen referencia a este coste que supone para el oyente el acceder a una información contextual y emplearla para derivar implicaciones contextuales. Desde luego, el hablante tenderá a producir cnunciados cuya interpretación implique el menor esfuerzo para el oyente, ya que éste da por supuesto que el hablante siempre emitirá mensajes que le supongan el mínimo esfuerzo de decodificación. A este hecho es a lo que estos autores denominaron principio de pertinencia. 
Mc.- $\quad$ hola $\neg$ ¿está <nombre propio > José María </nombre propio>? (No existe relación previa. Petición de conformidad)

I.- ¿de parte de quién? (Identificación formal)

Mc.- de <nombre propio > Mónica </nombre propio $>$. (Identificación formal)

En este caso la lógica de adyacencia también queda violada desde el momento en que a una primera parte de una secuencia interrogativa se le hace corresponder otra pregunta. Bien es cierto que la apertura conversacional con el interrogativo sí viene a ser una aceptación fática de la conversación que encierra una muestra de voz identificativa y la disponibilidad a hablar del sujeto antes que una secuencia interrogativa. Parece que en este caso la función fática de la apertura telefónica indicando el canal abierto viene a sustituir a la función propiamente interrogativa de la que sólo conservamos la entonación de la pieza léxica: sí=(interrogaciónentonación+afïrmación-apelación).

De cualquier modo, la propia interrogación segunda lleva consigo una respuesta afirmativa que el receptor es capaz de decodificar reafirmando con su identificación el principio de pertinencia.

c)

$<\mathrm{I}=$ hombre, 26 años, estudios superiores, parado $>$

$<\mathrm{P}=$ hombre, 30 años, estudios medios, representante $>$

$<$ origen $=\mathrm{I}=\mathrm{P}=$ Málaga $>$

$<$ roles $=\mathrm{l}=\mathrm{P}=$ amigos $>$

$<$ timbre>

I.- ¿quién es? (Disponibilidad. Conversación abierta+petición de identificación)

P.- soy <nombre propio $>$ Pedro $<$ /nombre propio $>$. (Identificación)

I.- hola <nombre propio > Pedro </nombre propio> ' buenos días. (Preámbulo $=$ saludo)

P.- <apelativa> dile a mi madre que se ponga 'anda </apelativa >. (Tema)

I.- un momentito.

Ahora el par de adyacencia queda roto, pues a un saludo no le corresponde otro saludo sino una apelación que es interpretada por el receptor de manera inmediata.

Normalmente, y también de forma básica, las aperturas conversacionales telefónicas son secuencias de apelación-contestación tras las cuales se deja expedito el canal para que la persona que efectuó la llamada exponga la causa que motivó la misma. Por lo tanto, la apelación que efectúa el emisor debe considerarse como el preámbulo que anuncia su intención, aunque también implica la disposición que el receptor muestra para atender el mensaje. Se trata, pues, de establecer un foco de comunicación en el cual los actores asumen su papel y se preparan para la comunicación. 
Ejemplo 4. Estructuras apelación-contestación

a)

$<\mathrm{Pp}=$ mujer, 35 años, sin estudios, ama de casa $>$

$<A=$ mujer, 25 años, estudios superiores, maestra $>$

$<$ origen $=\mathrm{Pp}=\mathrm{A}=$ Málaga $>$

$<$ roles $=\mathrm{Pp}=\mathrm{A}=$ conocidas $>$

$<$ timbre>

Pp.- ¿dígame? (Disponibilidad. Conversación abierta)

A.- hola soy <nombre propio $>$ Alonso </nombre propio $>$. (Saludo+identificación formal)

Pp.- $\quad$ sí ' ¿qué? (Reconocimiento+petición de tema)

A.- <apelativa $>$ mira </apelativa $>$.

Pp.- miro.

A.- que $(\rightarrow)^{\prime}$ 'el viernes <cláusula no completa $>$

Pp.- sí.

A.- tenemos reuniones.

b)

$<\mathrm{Q}=$ hombre, 30 años, estudios superiores, profesor $>$

$<A=$ hombre, 26 años, estudios superiores, investigador $>$

$<$ origen $=\mathrm{Q}=\mathrm{A}=$ Málaga $>$

$<$ roles $=\mathrm{Q}=\mathrm{A}=$ amigos $>$

$<$ timbre $>$

Q.- ¿sí? (Disponibilidad. Conversación abierta)

A. - <nombre propio $>$ Curro </nombre propio $>$. (Identificación+petición de reconocimiento)

Q.- <apelativa $>$ dime $<$ lapelativa $>$. (Reconocimiento+petición de tema)

A.- <apelativa $>$ escúchame </apelativa $>$.

Q.- sí.

A.- ¿vamos a estudiar esta noche?

En los ejemplos anteriores, y en realidad en la inmensa mayoría de las conversaciones telefónicas, existe un deseo implícito o explícito de la persona que efectúa la llamada por ser reconocido lo más rápidamente posible. El reconocimiento rápido de los interlocutores proporcionará fluidez a la conversación desde el principio y, en palabras de Levinson, evitará los posibles problemas originados por la falta de identificación y reconocimiento ${ }^{30}$. Además, el reconocimiento mutuo viene a nivelar en cierta manera la desventaja, a la que hacíamos más arriba referencia, con que parte el que recibe la llamada respecto a quien la realiza, pues éste, como queda dicho, conoce la identidad de la persona o institución a la que llama, mientras el que responde no la conoce en principio. Ahora bien, no todos los procedimientos de identificación disponibles para la identificación personal rápida poseen los mismos esquemas en la apertura de las conversaciones telefónicas y están sujetos al grado de amistad o de intimidad que exista entre los interlocutores, siendo a veces suficiente el timbre de una voz

30 S.C. LEVINSON (1983), pág. 298. 
amiga para ser identificado de inmediato (Cf. esquema general propuesto en página 51). Antes de pasar a observar estos procedimientos, debemos rescatar del conjunto de las llamadas telefónicas aquellas en las que la persona que recibe la llamada pregunta directamente a su interlocutor por su identificación, bien sea por un desconocimiento común o por un lapsus momentáneo. Normalmente, en el primero de los casos, quien realiza la llamada no tiene ningún interés en darse a conocer, pues quien se encuentra en ese momento al otro lado del teléfono no es el destinatario de su llamada.

Ejemplo 5. Apertura con reclamo de identificación

a)

$<\mathrm{Z}=$ hombre $>$

$<\mathrm{Mr}=$ mujer, 25 años, estudios superiores, maestra $>$

$<$ origen $=\mathrm{Mr}=$ Málaga $>$

$<$ roles $=\mathrm{Mr}=\mathrm{Z}=$ no existe relación previa $>$

$<$ timbre>

Z.- sí $\urcorner$ dígame. (Disponibilidad. Conversación abierta)

Mr.- hola $\neg$ ¿está <nombre propio> Mati </nombre propio>? (Saludotpetición de conformidad)

Z.- <nombre propio> Mati </nombre propio> ' sí // ¿quién es? (Conformidad efectuada+petición de identificación)

Mr.- soy una amiga.

b)

$<\mathrm{Mc}=$ mujer, 25 años, estudios medios, administrativo $>$

$<\mathrm{l}=$ hombre $>$

$<$ origen $=\mathrm{Mc}=$ Málaga $>$

$<$ roles $=\mathrm{Mc}=\mathrm{I}=$ no existe relación previa $>$

$<$ timbre>

1.- ¿sí? (Disponibilidad. Conversación abierta)

Mc.- hola $\neg$ ¿está <nombre propio> José María </nombre propio>? (Saludo+petición de conformidad)

I.- ¿de parte de quién? (Conformidad efectuada+petición de identificación)

Mc.- $\quad$ de <nombre propio> Mónica </nombre propio $>$.

En los casos de lapsus momentáneos, sí existe intención de ser reconocido aunque sea a través de una mínima muestra del timbre de voz, pero no siempre se consigue.

Ejemplo 6. Intento de identificación a través del timbre de voz $<\mathrm{J}=$ hombre, 32 años, estudios superiores, arquitecto técnico $>$ $<\mathrm{C}=$ hombre, 26 años, estudios superiores, investigador $>$ $<$ origen $=\mathrm{J}=\mathrm{C}=$ Málaga $>$

$<$ roles $=\mathrm{J}=\mathrm{C}=$ conocidos a través de terceros $>$

$<$ limbre $>$

J.- ¿sí? (Disponibilidad. Conversación abierta) 
C. - hola $^{-} i<$ nombre propio $>$ Jorge $<$ nnombre propio $>$ ? (Saludo+petición de conformidad)

J.- sî ¿quién es? (Conformidad efectuadatprueba de reconocimiento)

C.- ¿qué pasa $\neg$ que no me conoces? (Identificación débil)

J.- no " no caigo ¿quién es? (Prueba de reconocimiento)

C.- soy <nombre propio $>$ Carlos $</$ nombre propio $>$ (Identificación plena)

J.- <nombre propio $>$ Carlos </nombre propio $>$ ¿qué <nombre propio $>$ Carlos $<$ nombre propio $>$ ? (Prueba de reconocimiento)

C.- el hermano de $<$ nonbre propio $>$ Auxi $<$ /nombre propio $>$.

Salvando estas situaciones, y algunas otras formales o de negocios en las que la identificación es imposible y se efectúa de manera directa («soy fulanito de tal y quisiera...»), en todos los demás casos, como queda dicho, la identificación rápida cs deseable y se efectúa de distinta forma. La más básica, y posiblemente más generalizada, consiste en una intervención primera al descolgar el teléfono que puede ser considerada respuesta fática a la apelación del timbre telefónico seguida de un saludo o comprobación de identificación y cerrada con una nueva intervención que confirma plenamente la identificación mutua y la disposición a iniciar la comunicación esencial. En esquema, sería:

\section{Ejemplo 7. Identificación rápida}

a)

$<\mathrm{M}=$ hombre, 30 años, estudios superiores, profesor $>$

$<A=$ hombre, 26 años, estudios superiores, investigador $>$

$<$ origen $=\mathrm{M}=\mathrm{A}=$ Málaga $>$

$<$ roles $=\mathrm{M}=\mathrm{A}=$ amigos $>$

$<$ <imbre> (apelación)

M.- ¿sí? (Respuesta + prueba de reconocimiento)

A.- <nombre propio > Manolo </nombre propio > (Afirmación de reconocimiento + prueba de reconocimiento)

M.-dime (Respuesta + afirmación de reconocimiento + prueba de estar preparado para la comunicación)

b)

$<\mathrm{Al}=$ hombre, 28 años, estudios medios, empleado de fábrica $>$

$<\mathrm{A}=$ hombre, 26 años, estudios superiores, investigador $>$

$<$ origen $=\mathrm{Al}=\mathrm{A}=$ Málaga $>$

$<\mathrm{roles}=\mathrm{Al}=\mathrm{A}=$ amigos $>$

$<$ limbre> (apelación)

A.- ¿si? (Respuesta + prueba de reconocimiento)

Al.- ihola <nombre propio> Alfonsito </nombre propios! (Saludo $1^{a}$ parte + afirmación de reconocimiento + prueba de reconocimiento)

A.- ¡hola! (Saludo $2^{a}$ parte + afirmación de reconocimiento + prueba de estar abierto para recibir información) 
Estos ejemplos, tomados de conversaciones familiares, nos proporcionan suliciente información para afirmar que la apertura en este tipo de conversaciones consta de cuatro turnos bien diferenciados, de entre los que el primero requiere la atención del receptor (llamada misma); el segundo proporciona una primera identificación (contestación primera al teléfono diga, ¿sí?) ${ }^{31}$; el tercero representa una apelación al receptor que a veces puede tomar la forma de saludos, y el cuarto es la posibilidad que el receptor da al emisor para que inicie la interacción por medio de la segunda parte del saludo o de una nueva apelación. La estructura simplificada sería: apelación-contestación-primer tema, que desde el principio asigna los papeles de emisor y receptor a los participantes a través de unas reglas de participación coordinada. Este esquema básico puede sufrir alteraciones mínimas según el tipo de llamadas, pues pueden producirse preguntas de cortesía, previas al primer tema, para interesarse por la salud, la familia, etc., que pueden llegar a ser más o menos extensas según el grado de amistad entre los hablantes.

Ejemplo 8. Preámbulos al tema principal de la llamada

a)

$<\mathrm{B}=$ mujer, 59 años, sin estudios, ama de casa $>$

$<A=$ hombre, 26 años, estudios superiores, investigador $>$

$<$ origen $=\mathrm{B}=\mathrm{A}=$ Málaga $>$

$<$ roles $=\mathrm{B}=\mathrm{A}=$ familia $>$

$<$ timbre $>$

A.- ¿sí $\rightarrow)$ ? (Disponibilidad. Conversación abierta)

B.- <nombre propio $>$ Antonio </nombre propios. (Muestra de voz=identificación)

A.- <simultáneo ¿qué?

$<$ PREÁMBULO >

B.- ¿dónde $</$ simultáneo $>$ te metes esta mañana?

A.- pues que hemos esta $<$ (d) $>0$ comprando cositas.

B.- ¿qué has compra $<(d)>0$ hi $<(j)>0$ ? ' navidad.

A.- la navidad.

B.- $\langle$ risas $=B>$ ' <irónico $>$ como hace fresquito esta mañana ¿no? $<$ irónicos.

A.- claro // ihay que ver el día! ¿eh?

B.- juy $\urcorner$ por dios <nombre propio $>$ Antonio </nombre propio $>$ ! ' esto es horroroso ya ¿eh?

A.- menos mal que se ha encontra $<$ (d) $>0$ la bolsa esa de agua.

B.- (210) bueno $\mathrm{y}^{\prime}<$ vacilación $>$... y eso ¿qué es lo que quiere decir? / que vamos a tener agua $\mathrm{pa}<(\mathrm{r})><(\mathrm{a})>$ beber y $\mathrm{pa}<(\mathrm{r})><$ (a) $>$ lavarnos ' pero el campo ¿qué?

31 Como ya dijimos, estos dos primeros pasos pueden formar una unidad si lo consideramos como el inicio propiamente de la conversación telefónica, donde un sujeto A hace la llamada con la intención de entablar una conversación y un sujeto $\mathrm{B}$ descuelga el teléfono y responde, dando a entender su disposición a participar en ella, es decir, el sujeto B acepta el requerimiento proveniente de parte del sujeto $A$. 
A.- ¡ah! $\urcorner$ el campo igual.

B.- y la atmósfera ¿qué?

A.- hombre pero el agua que vayamos a utilizar nosotros $/ /$ po $<(\mathrm{s})>$ por lo menos ya la que íbamos a utilizar se ' se llevará al campo.

B.- dice que $(\rightarrow) /$ que hay pa $<(\mathrm{r})><(\mathrm{a})>$ tres años $₫$ no?

A.- sí $\urcorner$ pero en tres años si no llueve se acaba también.

B.- ¡coño ' ¿pero va a estar tres años sin llover?!

A.- ¡yo qué sé mamá!

B.- janda ya hombre! ' si agua $\neg$ tiene que $<$ corrección $>\urcorner$ tiene que llover a cántaros como ha llovi $<$ (d) $>0$ siempre / lo que pasa es que esto es una sequía $m u<(y)>$ grande que estamos atravesando $\urcorner$ y se acabó.

A.- $\sin ^{\wedge}$ pero en $<$ nombre propio $>$ Inglaterra $<$ /nombre propio $>$ mira lo que ha pasa $<$ (d) $>0$.

B.- ¿qué ha pasa<(d)>0?

A.- ¡digo! $\neg$ que como ha cambia $<$ (d) $>0$ el tiempo pues ya han puesto allí las rebajas de invierno en la $<$ risas $=B>$ ropa y to $<$ (d) $><($ o $)><$ risas $=B>$.

B.- (220) ¡qué embustero eres!

A.- $<$ simultáneo $>$ ¡qué es verdad!

B.- y aye $\langle$ palabra cortada $>$... $</$ simultáneo $>$ ' ayer dijo el tío del tiempo que hace mucho frío ya por ahí.

A.- ¡sî́ hombre!

B.- iqué lo dijo!

A.- po $<(\mathrm{s})>$ la radio ha dicho eso ${ }^{-}$mamá $\neg$ hoy.

B.- bueno po<(s)> que ' anoche dijo que <estilo indirecto $>$ por ahí había cambia $<$ (d) $>0$ ya el ti $<$ palabra cortada $>$... ' estaba cambiando que hacía $<$ corrección $>$ la temperatura era de nueve grados </estilo indirecto $\rangle$.

A.- digo $\neg$ de nueve grados $\neg$ nueve grados a esta altura de año es $<$ simultáneo $>$ na $<(\mathrm{d})><(\mathrm{a})>$.

B.- pero hombre $</$ simultáneo $>$ todavía nueve grados $\neg$ todavía estamos a principios de noviembre ' <nombre propio $>$ Antonio </nombre propio $>$.

A.- bueno $\neg$ ya veremos.

B.- bueno $\neg$ ya veremos ' $<$ irónico $>$ bueno po $<(\mathrm{s})>$ vamos $t o<(\mathrm{d})><(\mathrm{o})>$ el año en bikini $\langle$ /irónico $>\langle$ interrupción $=A\rangle$

A.- aquí estamos hoy a treinta.

B.- ¿estamos ya a treinta?

A.- claro.

B.- tú ya lo has visto ¿no? / <fático=afirmación $=A>/$ no $\neg$ pero está refrescando ahora.

A.- <irónico $>$ sí $<$ irónico $>$.

$</ P R E A ́ M B U L O>$

B.- <apelativa $>$ escúchame $<$ apelativa $>/ /$ a ti te importa irte a $<$ sic $>$ en casa $<$ (d) $><$ (e) $>$ tu hermana?

b)

$<\mathrm{Al}=$ hombre, 28 años, estudios medios, empleado de fábrica> $<A=$ hombre, 26 años, estudios superiores, investigador $>$ $<$ origen $=\mathrm{Al}=\mathrm{A}=$ Málaga $>$ 
$<$ roles $=\mathrm{Al}=\mathrm{A}=$ amigos $>$

$<$ timbrc>

A.- ¿si? (Disponibilidad. Conversación abierta)

Al.- ¡hola <nombre propios Alfonsito </nombre propio >! (Saludo+muestra de voz=identificación)

A.- ¡hola $\rightarrow)$ !

\section{$<$ PREÁMBULO>}

Al.- ¿qué haces? ' no encontrabas el teléfono.

A.- no $\neg$ ahora mismo <ruido=respiración sofocada $\rangle\langle$ cláusula no completa $><$ interrupción $=A l>$

Al.- $\quad$ has entrado por las puertas.

A.- he entra $<$ (d) $>0$ por la puerta $<$ ruido=respiración sofocada $>$.

Al.- $\quad$ y estabas viendo el fútbol / <simultáneo> y lo has <cláusula no completa>

A.- no $</$ simultáneo $>$.

Al.- $\quad y$ lo has teni< $<$ d $)>0$ que dejar por ver ' por la mitad.

A.- no $(\rightarrow)$ ᄀ ¡qué va! ' si es que vengo ahora mismo de recoger a la perra $<$ cláusula no completa>

Al.- ¡ah!

A.- en casa de mi abrela.

Al.- jah!

A.- precisamente hemos pasa $<$ (d) $>0$ por allí por tu casa $\rightarrow$ y hemos mira $<$ (d) $>0$ pa $<$ (r) $><$ (a) $><($ a $)>$ rriba y no había // no había luz.

Al.- Sí $\neg$ es que hemos esta $<(d)>0$ en la peluquería $<$ fático $=$ afirmación $=A>$ y acabamos de llegar.

A.- , $\left.\mathrm{pa}<(\mathrm{r})\rangle\langle(\mathrm{a})\rangle{ }^{\prime} \mathrm{pa}<(\mathrm{r})\right\rangle\langle(\mathrm{a})\rangle$ ti o $\left.\mathrm{pa}<(\mathrm{r})\right\rangle\langle(\mathrm{a})\rangle<$ nombre propio $>$ Joselita $</$ nombre propio $>$ ?

Al. $-(270)$ pa $<(\mathrm{r})><(\mathrm{a})>$ los dos.

A.- $<$ simultáneo $>$; $a h^{\urcorner} \operatorname{los}$ dos!

Al.- $\quad$ es $<$ palabra cortada $>$... ' espérate $\langle/$ simultáneo $\rangle$ ¿qué dices nena? $/ /$ ¡ah sí! $\neg$ que hemos esta<(d) $>0$ en la peluquería y os hemos llama $<$ (d) $>0 ~ \neg$ porque como os dijimos que <estilo indirecto $>$ fbamos a estar aquí a las ocho por si os veníais a estudiar $</$ estilo indirecto $\rangle\langle$ cláusula no completa $\rangle$

A.- sí.

Al.- $\quad$ hemos sali $<(\mathrm{d})>0$ dos o tres veces a llamar fuera $\langle$ risas $=A l>$.

A.- $<$ simultáneo $>$ no $\rightarrow$ es que $\langle$ interrupción $=A l>$

Al.- $\quad$ es que el $</$ simultáneo $>$ peluquero $\neg$ quedamos a las seis $\neg$ tío $\neg$ hemos termina $<(d)>0$ a las nueve.

A.- oye ${ }^{-}$y ¿qué peluquero es ese tan ocupa $<(d)>0$ ?

Al.- el ${ }^{-h}$ que va <nombre propio> Melina </nombre propio> $/ 1$ $<$ simultáneo $>$ ese de ahí al la $<$ (d) $>0$.

A.- ¡ah! $</$ simultáneo $>$ sí ' po<(s)> mira precisamente hemos ' hemos pasa $<$ (d) $>0$ por ahí por la puerta $<$ cláusula no completa $>$

Al.- ¡ajá! 
A.- y lo hemos visto $\mathrm{y}\urcorner$ le he dicho a $<$ nombre propio $>$ Melina $<$ /nombre propio $><$ estilo directo $>$ fijate el <nombre propio $>$ Carlitos $<$ nombre propio $>$ cómo está este $\urcorner$ cómo está este sábado.

Al.- $\quad$ po $<($ s $)>$ yo estaba senta $<$ (d) $>0\urcorner$ tío allí $<$ risas $=$ Al $>$.

A.- estabas allí $/<$ fático=afirmación $=A l>$ ' tú eras uno de los que estaba ocupándolo.

Al.- $\quad$ sí $(\rightarrow)\urcorner$ que estaba conmigo el <nombre propio $>$ Carlitos $</$ nombre propio>.

A.- sí $^{-}$¿no?

Al.- $\quad$ sí $\urcorner$ uno que le ha deja $<$ (d) $>0$ un pela $<$ (d) $>0$ de maricón ique no veas! / $<$ risas $=A>$ ese era yo.

A.- te ha deja $<$ (d) $>$ o bien ¿no?

Al.- $\quad$ sí $^{-}$bien amaricona $<$(d) $>0<$ risas $=A l>$

A.- bucno / pero eso no hace falta que se emplee mucho contigo.

Al.- (280) no ${ }^{-}$ya sí $^{-1}$ pero $<$ risas $=A=A l>$ con que me peine.

A.- no ${ }^{\urcorner}$hombre.

$</ P R E A ́ M B U L O>$

Al.- mira ' ¿vais a venir a estudiar o qué?

También es cierto que, a veces, en este esquema básico, sobre todo en conversaciones muy familiares, los interlocutores pueden dar por supuesto que el reconocimiento se realizará sin mayores problemas y omiten todo este protocolo inicial de apertura. En este caso, los conocimientos compartidos y la interacción entre los hablantes es máxima y el esquema situacional no puede dar lugar a equívocos.

Ejemplo 9. Introducción al tema principal sin preámbulos

$<\mathrm{C}=$ hombre, 30 años, estudios superiores, profesor $>$

$<A=$ hombre, 26 años, estudios superiores, investigador $>$

$<$ origen $=\mathrm{C}=\mathrm{A}=$ Málaga $>$

$<$ roles $=\mathrm{C}=\mathrm{A}=$ familia, amigos $>$

$<$ timbre>

C.- ¿sí? (Disponibilidad. Conversación abierta)

A.- ¿has graba<(d)>0 <nombre propio $>$ Carlos < inombre propio $>$ ? (Rclación muy fuerte. Tema)

C.- no $\urcorner$ porque no ha habi< $<$ d $)>0$ reunión.

Tras el esquema de apertura, la persona que realizó la llamada tiene libre el camino para exponer la razón de la misma. Se considera que el primer tema está casi siempre libre de las restricciones que van a influir sobre el resto de la conversación telefónica, ya que al considerarse como el tema principal de la llamada no estará expuesto a adaptarse a otros anteriores. En esto tienen mucho que ver, otra vez, las características situacionales que identifican a las llamadas telefónicas y, en concreto, la restricción de canales que poseen los hablantes. En 
las conversaciones cara a cara, los participantes se valen de distintos medios para reconducir la conversación, adaptarla a los temas que más les interesen u obviar otros no deseados por medio de todo tipo de gestos, miradas o interrupciones. La capacidad de intervención en las llamadas telefónicas está mucho más limitada y los temas irán saliendo a colación siempre que haya oportunidad de exponerlos, con lo cual podemos considerar que los temas en las conversaciones telefónicas van enlazados la mayoría de las veces, siendo frecuente que los interlocutores esperen el momento en que esos temas se adapten a otros anteriores para introducirlos. Lógicamente, el único tema libre de este tipo de adaptación es el primero, aunque ni siquiera siempre resulta así, pues el tema principal de una llamada puede llegar a necesitar adaptación a la situación, sobre todo cuando el preámbulo que comentábamos antes se alarga demasiado. Ahora bien, ¿qué ocurre si no se encuentra el momento de introducir un tema concreto?; ¿cómo solucionan los hablantes la no adaptación de sus intereses temáticos al conjunto de la conversación? La falta de canales comunicativos obliga en estos casos a los hablantes a realizar un salto temático marcado por una serie de rasgos prosódicos concretos como el incremento de la amplitud, elevación de tono, marcadores concretos de autocorrección, vacilación, etc. encaminados a la reconducción de la comunicación.

Veamos algunos ejemplos que van desde el esquema básico de apertura seguido por la introducción del tema principal, hasta el uso de todo tipo de rasgos prosódicos empleados por un hablante para efectuar un salto temático.

Ejemplo 10

a) esquema básico

$<A r=h o m b r e, 30$ años, estudios superiores, empleado de banca $>$

$<A=$ hombre, 26 años, estudios superiores, investigador $>$

$<$ origen $=\mathrm{Ar}=\mathrm{A}=$ Málaga $>$

$<$ roles $=\mathrm{Ar}=\mathrm{A}=$ amigos $>$

$<$ timbre>

Ar:- $\quad$ ¿diga? (Disponibilidad. Conversación abierta)

A.- <nombre propio $>$ Arturo </nombre propio $>$.

Ar.- dime.

A.- ¿vais a venir esta noche?

Ar. $-\quad<$ ruido $=t o s=A r>$ sí $\neg$ claro.

b) salto 1. Introducción del tema principal tras un preámbulo $<\mathrm{L}=$ mujer, 28 años, estudios medios, administrativo $>$

$<A=$ hombre, 26 años, estudios superiores, investigador $>$

$<$ origen $=\mathrm{L}=$ Madrid $>$

$<$ rigen $=\mathrm{A}=$ Málaga $>$

$<$ roles $=\mathrm{L}=\mathrm{A}=$ conocidos $>$

$<$ timbre>

A.- ¿sí? (Disponibilidad. Conversación abierta) 
L.- hola $\urcorner$ buenos días $\urcorner$ ¿<nombre propio $>$ Andrés < $<$ nombre propio $>$ ?

A.- sî́ $\urcorner$ soy yo.

L.- hola - mira ' te llamo desde la <nombre propio $>$ Universidad $<$ /nombre propios.

A.- ¡ah! ' ¿qué hay? ' buenos días.

L.- <vacilación>... Ilamaste ayer por teléfono <cláusula no completa $>$

A.- $<$ simultáneo $>$ sí. estás?

L.- para $\rightarrow)</$ simultáneo $>$ preguntarnos unas cosas '¿qué tal? '¿cómo

A.- muy bien ' gracias " $\mathrm{y}$ y vosotros?

L.- tirando " tú dirás.

A.- muy bien "verás es que me gustaría veros para comentar un par de cosillas.

c) Salto 2. Cambio de tema.

$<\mathrm{J}=$ hombre, 43 años, estudios superiores, profesor $>$

$<\mathrm{A}=$ hombre, 27 años, estudios superiores, profesor $>$

$<$ origen $=\mathrm{J}=\mathrm{A}=$ Málaga $>$

$<$ roles $=\mathrm{J}=\mathrm{A}=$ conocidos, compañeros de trabajo $>$

J.- $0<$ vacilación $>\ldots$ o vienes $\neg$ a otra hora.

A.- o voy a otra hora $\urcorner$ vale.

J.- otro día vamos ' cuando tú quieras.

A.- <vacilación $>\ldots$ vamos a ver <vacilación $>$... tú ' ¿por qué no me das el teléfono de $\rightarrow$ ) ' de <nombre propio $>$ Manolo < nombre propio $>$ ?

J.- sí.

A.- que me dijo que <estilo indirecto $>$ lo llamara antes de pasar por su casa $</$ sillo indirecto $\rangle<$ simultáneo $\rangle$ pero yo no lo tengo.


propio $>$ Málaga </nombre propio $>$ ¿no?

A.- sí $^{\top}$ de aquí de su casa.

J.- mira $\urcorner$ apunta.

A.- dime.

...

A.- vale $/ /$ mu $<(y)>$ bien.

J.- ¿vale?

A.- de acuerdo.

J.- muy bien.

A.- <vacilación $>$... va <palabra cortada $>$... $<$ tono alto $>$;ah ' otra cosa! $</$ tono alto $>$.

J.- dime.

A.- lo último ya ' mira // <vacilación >... ¿te llamó a ti <nombre propio> María José < hombre propio >?

En la secuencia en negrita el hablante recurre a ciertos rasgos prosódicos (vacilación, cambio de tono y dudas) para reconducir la conversación y orientar la misma hacia otro tema que le interesa particularmente. 
Si atendemos ahora a la conclusión de las llamadas telefónicas, podemos observar, aún más claramente si cabe, que los hablantes se adaptan y asumen un esquema básico de cierre que, en la mayor parte de los casos posee una serie de elementos de pre-conclusión ordenados como auténticos turnos de paso y un intercambio de saludos finales de despedida. A ello, casi siempre va unida la inclusión de algún tema prototípico de finalización donde se hacen planes o se ofrecen recuerdos para la familia, etc. Todo ello conduce a los hablantes a la salida ordenada de la conversación. Queremos dar especial realce a los elementos de pre-conclusión, mediante los cuales los hablantes se ceden el turno de palabra y asumen el acuerdo de no hablar más y dar por terminada la conversación (vale, de acuerdo, muy bien, bueno...). En el momento en que una de las partes no tienc más que decir introduce un elemento de pre-conclusión que será respondido por la otra parte si tampoco tiene más que decir. La aceptación del cierre de la conversación por medio de los elementos de pre-conclusión es un claro ejemplo de la intcracción que existe entre las dos partes y soluciona un problema que algunos sociólogos han considerado como delicado, pues podría surgir un conflicto tanto si prolongamos demasiado el período de conclusión como si uno de los participantes da por terminada la conversación quedando algo que decir por parte del otro participante. Pues bien, en este sentido, la introducción de los elementos de pre-conclusión indican, por un lado, el deseo de una de las partes por finalizar el proceso, a la vez que se ofrece la posibilidad a la otra parte de cerrarla definitivamente o de añadir algo más si se desea. Los elementos de preconclusión son diversos y son tan comunes en las conversaciones telefónicas que muchas veces la introducción de uno de estos elementos de pre-conclusión va scguido directamente del saludo de despedida, pues la carga significativa que encierran es conocida de sobra por los hablantes.

Ejemplo 11. Cierre de conversación telefónica introducido por elementos de pre-conclusión

$<\mathrm{M}=$ hombre, 30 años, estudios superiores, funcionario $>$

$<\mathrm{A}=$ hombre, 26 años, estudios superiores, investigador $>$

$<$ origen $=\mathrm{M}=\mathrm{A}=$ Málaga $>$

$<$ roles $=\mathrm{M}=\mathrm{A}=$ familia, amigos $>$

M.- cl otro <vacilación $>$... bien $\urcorner$ la verdad es que está bien $\urcorner$ bueno tosiendo y tal pero vaya $\urcorner$ que no parece que tenga mucho.

A.- vaya dos lines de semana $(\rightarrow)^{\prime}$ ' 2 eh?

M.- ijo $<$ (d) $>$ er! $<$ ruido $=$ resopla $><$ risas $=A>$ ' bueno.

A.- hasta luego.

M.- hasta luego.

Puicde ocurrir también el hecho anómalo de que después de un intercambio de pre-conclusiones se reabra la comunicación. En estos casos, la reapertura es sentida por los interlocutores como extraña y también suele ir precedida por 
nucvas apelaciones o rasgos prosódicos característicos que ayuden a reabrir la comunicación:

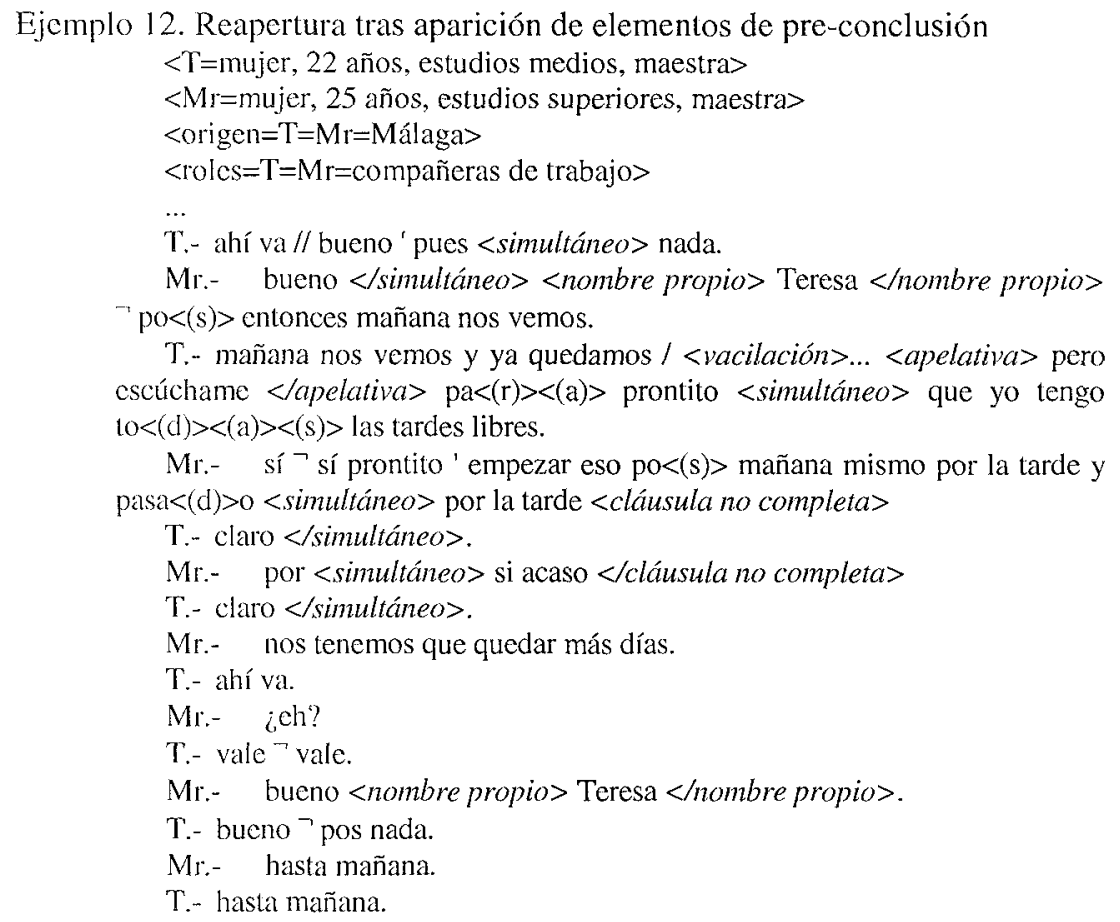

\section{Conclusiones}

A través de este estudio, hemos puesto de manifiesto un mecanismo de intervención que actúa sobre los participantes en este tipo de comunicación oral. La ordenada transición de un hablante a otro y la puesta en marcha del sistema comunicativo funciona gracias a una estructura ordenada subyacente al proceso y asumida de manera implícita por los hablantes. Gracias a este sistema nos introducimos en el proceso comunicativo y salimos de él de manera ordenada.

El intercambio de mensajes por medio de turnos de palabra se efectúa a través de una organización estructurada que regula precisamente las alternancias de los cilados turnos. Estc mecanismo indica el lugar y el momento en los que los interlocutores consideran factible la aparición de secuencias marco y el desarrollo de las mismas ejerciendo un control sobre ellas.

Las características situacionales especialmente limitadas de la conversación telelónica condicionan ampliamente sus rasgos de organización. En primer lugar porque los participantes no poseen diversidad de canales a través de los cuales 
transmitir los mensajes. Sin duda, el principal canal es el propio aparato telelónico, pero uno de los rasgos que definen al lenguaje oral es, precisamente, el de poseer multicanales de expresión (gestos, contactos físicos, miradas...). Las conversaciones a través del teléfono acotan mucho el número de subcanales, que pueden reducirse a la entonación, cambios de tempo, volumen y silencios. Quizás la propia limitación de vías de expresión sea uno de los motivos que exigen en este tipo de conversaciones unas secuencias de apertura y cierre claras, bien conocidas por los participantes para evitar confusiones y situaciones embarazosas y, sobre todo, flexibles en su ejecución, donde el par de adyacencia pueda en ocasiones ser roto y sustituido por el principio de preferencia, donde, dada una primera parte, una segunda es esperable, pero si no es así, las expectativas planteadas han de ser atendidas por otros medios recurrentes en el propio esquema comunicativo ${ }^{32}$.

\section{Referencias bibliográficas}

BLAKEMORE, D. (1992): «La organización del discurso», en Panorama de la lingiuística moderna de la Universidad de Cambridge, vol. IV, El lenguaje: contexto sociocultural, Madrid, Visor, págs. 275-300, especialmente 277 en adelante.

BLECUA, J. M. (1982): ¿Qué es hablar?, Aula Abierta Salvat, Madrid, Salvat.

BRIZ, A. (coordinador) (1995): La conversación coloquial. Materiales para su estudio, Anejo $\mathrm{n}^{\circ}$ XVI de la Revista Cuadernos de Filología, Valencia, Universidad de Valencia.

CESTERO MANCERA, A. M. (1994): Análisis de la conversación: Alternancia de turnos en la lengua española. Tesis doctoral. Departamento de Filología, Facultad de Filosofía y Letras, Universidad de Alcalá de Henares.

CORTÉS, L. (1996): Español hablado. Bibliografía sobre aspectos teóricos y empíricos (morfosintácticos y sintáctico-pragmáticos), Anejos del Anuario de Estudios Filológicos, Cáceres, Universidad de Extremadura.

DIJK, T. VAN: Texto y contexto, Madrid, Cátedra, 1984.

FURBERG, M. (1971): Saying and Meaning, Oxford, Blackwell.

GALLARDO PAÚLS, B. (1990): «Discurso y conversación», en LÓPEZ GARCÍA, Á. et alii (eds.), Lingüística general y aplicada, Valencia, Universidad de Valencia.

GALLARDO PAÚLS, B. (1991a): «En torno a la preferencia como concepto del análisis conversacional», en LÓPEZ GARCÍA, Á. y RODRÍGUEZ CUADRADOS, E. (eds.): Miscel-lània Homenatge Enrique García Díez, Valencia, Universidad de Valencia.

GALLARDO PAÚLS, B. (1991b): «Pragmática y análisis conversacional: hacia una pragmática del receptor», Sintagma, 3.

En realidad, este es en síntesis el planteamiento crítico que S.C. LEVINSON (1983) realiza sobre el esquema general del par de adyacencia planteado por E. A. SCHEGLOFF y H. SACKS (1973) señalado en la nota 5. 
GALLARDO PAÚLS, B. (1992): «El dinamismo conversacional: subsunción y feed-back. Carácter acumulativo de los elementos conversacionales», en Comunicación y Sociedad, vol. 5, 1 y 2, 1992.

GALLARDO PAÚLS, B. (1993a): Linguiistica perceptiva y conversación: secuencias, Minneapolis-Valencia, University of Minnesota-Universitat de València, (Lynx, annexa, 4).

GALLARDO PAÚLS, B. (1993b): «La transición entre turnos conversacionales: silencios, solapamientos e interrupciones», en Contextos, XI/21-22, 1993.

GAZDAR, G. (1979): Pragmatics: implicature, presupposition and logical form, Nueva York, Academic Press.

GODARD, D. (1977): «Some setting, different norms: phone call beginnings in France and the United States», en Language in Society, vol. 6, $\mathrm{n}^{\circ} 2$.

GOODWIN, C. (1979): «The Interactive Construction of a Sentence in Natural Conversation», en PSATHAS, G. (ed.): Everyday Language: Studies in Ethnomethodology, New York, Irvington.

GRICE, P. H. (1975): «Logic and Conversation», en COLE, P. y MORGAN, J. L. (1975): Syntax and Semantics 3: Speech Acts, New York, Academic Press.

GUMPERZ, J. (1982): Discourse strategies, Cambridge, Cambridge University Press.

HALLIDAY, M. A. K. y HASAN, R. (1977): Cohesion in English, Londres, Logman.

KENDON, A. (1982): «The organization of behavior in face to face interaction. Observations on the development of a methodology», en SCHERER, K. R. y EKMAN, P. (eds.): Handbook of Methods in Non Verbal Behavior Research, Cambridge, Cambridge University Press, 1982, págs. 441-505.

LEVINSON, S. C. (1983): Pragmática, Barcelona, Teide (1989).

MORENO, F. (1988): Sociolingüística en EE. UU. (1975-1985). Guía bibliográfica crítica, Málaga, Ágora.

MORENO, F. (1986): «Sociolingüística de los rituales de acceso en una comunidad rural», Lingüística Española Actual, VIII. 2 , págs. 245-267.

MORENO, F. (1989a): «Análisis lingüístico de actos de habla coloquiales I», Español Actual, 51.

MORENO, F. (1989b): «Análisis lingüístico de actos de habla coloquiales It», Español Actual, 52.

MORENO, F. (1989c): «Elementos no marginales en la lengua coloquial de los jóvenes», en RODRÍGUEZ GONZÁLEZ, F. (ed.), Comunicación y lenguaje juvenil, Madrid, Fundamentos.

POYATOS, F.: «Interactive functions and limitations of verbal and non verbal behavior in natural conversations», Semiótica, 30, 3/4.

SACKS, H., SCHEGLOFF, E. y JEFFERSON, G. (1974): «The simplest systematics for the organization of turn taking for conversation», en GUMPERZ, J. y HYMES, D.: Discourse strategies, Cambridge, Cambridge University Press, 1982. 
SCHEGLOFF, E. (1982): «Sequencing in Conversational Openings», en GUMPERZ, J. y HYMES, D.: Discourse strategies, Cambridge, Cambridge University Press, 1982.

SCHEGLOFF, E. y SACKS, H. (1973): «Opening up closing», Semiótica, 7.4.

SEARLE, J. R. (1971): Philosophy of Language, Oxford, Oxford University Press.

SPERBER, B. y WILSON, D. (1986): Relevance: communication and cognition, Oxford, Blackwell.

SPERBERG-McQUEEN, C. M. y BURNARD, L. (1990): Guidelines for the Encoding and Interchange of Machine-Readable Texts, edición española de MARCOS MARÍN, F. A., Manual para la codificación e intercambio de textos informatizados. Normas de la Text Encoding Initiative, Sociedad Estatal V Centenario, Madrid, 1992.

STRAWSON, P. F. (1964): «Intention and convention in speech acts», en Philosophical Review, 73, reimpreso en SEARLE, J.R. (1971).

VILLENA PONSODA, J. A. (1994): La ciudad lingiuística, Granada, Universidad de Granada.

WEST, C. y ZIMMERMAM, D. (1982): «Conversation Analysis», en SCHERER, K. y EKMAN, P. (eds.): Handbook of Methods in Nonverbal Behavior Research, Cambridge, Cambridge University Press. 